\title{
Editorial
}

\section{A New Ecosystems Ecology for Anthropology}

\author{
Thomas Abel and John Richard Stepp
}

\section{INTRODUCTION}

Conversation between anthropology and ecosystems ecology was interrupted in the early 1980s, due to several well-reasoned critiques (Vayda and McCay 1975, Ellen 1982, Smith 1984, Winterhalder 1984, Moran 1990) of then-popular applications of ecosystems theory in anthropology (Rappaport 1968, Kemp 1969, Thomas 1973, 1976) and due, especially perhaps, to the appearance of promising alternative ecological (Vayda 1983, Winterhalder 1984) and evolutionary (Cavalli-Sforza and Feldman 1981, Boyd and Richerson 1985, Rindos 1986, Durham 1991) paradigms and programs. Since then, ecosystems ecology has been both refined and transformed by the study of complex systems, with its radical critique of science (Odum 1983, Prigogine and Stengers 1984; Salthe 1985; Holling 1986, Wicken 1987). The resulting "new ecology" answers most of the early criticisms of ecosystems (Scoones 1999: 481-483), and proposes theory and methods to address the dynamics of ecosystems as complex systems.

Today, worldwide interest in ecosystems ecology has resurged, as shown by its prominence in publications and university curricula, initiatives such as the Millennium Ecosystem Assessment, and new journals such as Ecosystems and Conservation Ecology. It has persevered, in part, because the criticisms of the 1970s and 1980s were heeded. Gone is the overriding concern with equilibrium systems, climax communities, and simple deterministic models. In its place is an ecosystems ecology that views ecosystems as complex adaptive systems that possess intriguing structural qualities, such as resilience, hierarchy, scale, nesting, dissipative structures, and autocatalytic design, and descriptors of dynamics, such as nonlinearity, irreversibility, self-organization, emergence, development, directionality, history, coevolution, surprise, indeterminism, pulsing, and chaotic dynamics.

While ecosystems ecology was being redefined, the situation in anthropology was far from stagnant. It would seem today that anthropology and the other social sciences have embraced ecology as never before. An explosion (perhaps surfeit) of ecologicalenvironmental specializations is now spreading through academic departments, including historical ecology, environmental history, political ecology, ecofeminism, environmentalism, environmental justice, symbolic ecology, ethnoecology, human ecology, evolutionary ecology, environmental anthropology, ecological anthropology, ecological economics, sustainable development, traditional ecological knowledge (TEK), conservation, environmental risk, and liberation ecology. A number of insightful reviews have been produced (Biersack 1999, Kottak 1999, Little 1999, Scoones 1999). According to Scoones (1999), however, the social sciences have not yet incorporated the "new ecology" of ecosystems or complex systems theory into their conceptualizations. He writes that the "theoretical framings" of the social sciences often presuppose the "discussions of environment on an equilibrial view, excluding the chance of engagement with newer debates in ecology" (Scoones 1999: pp. 489). However, he does see some hopeful signs in the successes of environmental history, in new studies of structure, agency, and scale, and in case studies of adaptive management and institutional context.

\section{ECOSYSTEMS ECOLOGY AND ECOSYSTEMS MANAGEMENT}

With so many "ecologies" to choose from, why should anthropologists be interested in ecosystems ecology and complex systems more generally? Ecosystems ecology is a systems science, one that studies both the biota and its physical environment, located in a specific place (Pickett and Cadenasso 2002). It is a relatively young field (Tansley coined the term "ecosystem" in 1935) that has achieved disciplinary status only in recent decades, but it has been a focus of theory and research for much of the last century (see Golley (1993) or Hagen (1992) for early histories; see 
Pace and Groffman (1998) or Vogt et al. (1997) for assessments of the current state of ecosystems research). With the environmental awakening of the 1960s and 1970s, ecosystems research achieved notoriety for identifying and assailing complex environmental problems, such as pesticide biomagnification, eutrophication of lakes, and acid rain (Groffman and Pace 1998). Although in many ways a problem-driven discipline (Groffman and Pace 1998), ecosystems science has been a superior testing ground for theories of systems, including current research into complex systems (Odum 1983, O'Neill et al. 1986, Ulanowicz 1986, Holling 1987, Levin 1999).

Ecosystems have been variously defined throughout their history (Tansley 1935, Odum 1953, Kimmins 1987). Vogt et al. (1997) provide a current list of important components of an ecosystems definition (Table 1). Following Tansley (1935) and Odum (1953), Pickett and Cadenasso (2002) flexibly define ecosystems as "any size so long as organisms, physical environment, and interactions can exist within it... [It can] therefore be as small as a patch of soil supporting plants and microbes; or as large as the entire biosphere of the Earth." We support this definition because it stresses the importance of place and the hierarchical scaling of the biosphere. In addition, it facilitates human ecosystems studies at regional and world systems scales.

The "applied" component of ecosystems science is "ecosystems management," which incorporates ecosystems theory into practical problem solving within state and regional bureaucracies (Vogt et al. 1997). Ecosystems management requires active management of both the human and non-human components of ecosystems. Its currently popular form, "adaptive management" (Holling 1978, Walters 1986), is ecosystems management that emphasizes the complex-systems features of learning, incomplete understanding and surprise, multi-scaled cause and effect, and hierarchical organization. It incorporates the adaptive cycle model of ecosystem dynamics - a general pattern with four phases: exploitation, conservation, crisis, and reconfiguration (Holling 1987). Adaptive management improves both the production and implementation of ecosystems management policy by reconceptualizing management as a dynamic and contingent process that responds at different times to the actions of bureaucrats, activists, "catalysts," and decision makers (Gunderson et al. 1995). Three articles in this special issue productively apply the adaptive cycle model to human ecosystems studies (Peterson et al. 2003, Toledo et al. 2003, Trosper 2003).

Again, therefore, why should anthropologists be interested in ecosystems ecology and complex systems more generally? First, who can deny the continuing need to address environmental problems and their impacts on people and culture? Food production and sustainability, fresh water limits, global warming, deforestation, biodiversity loss are all complex human-environmental problems with linked bioticphysical components; ecosystems ecology is an obvious choice for their study. Of even more general concern, humans rely on the productivity of ecosystems for nearly all of their material culture (save fossil fuels and metals) - on which the world supports 6 billion people. Anthropologists interested in understanding the present, historic, and prehistoric provisioning of humanity, and its countless related effects, should consider ecosystems and complex systems as models of structure, function, and dynamics that can be applied to "human ecosystems" studies. There are other reasons why ecosystems ecology should be of interest to anthropologists (see Moran 1990), but we will not attempt a thorough review here. Rather, we take this opportunity to explore more fully the promising implications of complex systems theory for ecosystems science and the study of humans therein.

\section{COMPLEX SYSTEMS AND THE NEW ECOLOGY}

Simon Levin (1998) characterizes ecosystems as "prototypical examples of complex adaptive systems." Complex systems may be less familiar to the social science audience of this special issue, therefore, a general, albeit incomplete, introduction is provided. First, what actually constitutes complex systems science is not yet settled. Although there are many threads, we and others (Depew and Weber 1995) see an integrated, evolutionary science of complex systems emerging from the synergy between new computational paradigms (chaos theory, agent-based modeling, and self-organization) (Kauffman 1993, Gell-Mann 1994, Holland 1995), dramatic breakthroughs in the venerated field of nonequilibium thermodynamics (Prigogine 1980), empirical research into large, complicated systems such as weather, earth systems, and ecosystems (Odum 1983, O'Neill et al. 1986, Ulanowicz 1986, Holling 1995, Levin 1999), and innovation in evolutionary theory (Salthe 1985, Wicken 1987, Brooks and Wiley 1988, Depew and 
Weber 1995, van de Vijver et al. 1998). As an emerging field, some researchers claim their part as the whole, but we prefer to see the connections and the possibilities of an open, multi-disciplinary, evolutionary, and integrative systems science.

Table 1. Important ecological components of any ecosystem definition (Vogt et al. 1997:71-72)

1. Integration of all biological (biotic) and nonbiological (abiotic) parts

2. Monitoring the movement of energy and materials (including water, chemicals, nutrients, pollutants, etc.) into and out of its boundaries

3. Utilization of a common currency called energy to measure ecosystem function and the strength of the links between different ecosystem components. In practice, changes in organic matter or carbon accumulation (i.e., net primary production) over a defined space and over a given time period is used as a surrogate for energy because photosynthesis, which fixes carbon, is an energy-assimilating process

4. Boundary definitions - a site that can be bounded by identifying the smallest unit that is self-sustaining

5. Explicit incorporation of spatial and temporal scales

6. Encompassing system or species characteristics that are highly interdependent and have strong feedback loops. Feedback loops can be expressed at the species or ecosystem level (i.e., keystone or functional groups) and can be driven by microbes and/or consumers

7. Incorporating disturbance cycles at defined temporal and spatial scales, explicitly acknowledging that disturbances can occur at varying scales and are an integral part of ecosystems. Identifies the importance of legacies (imprint of past disturbances or structures) and how they have contributed to the development of the current ecosystem structure and function

8. Characterization of all of the above for the multiple states that a system can fluctuate between as part of the natural development of that system

Complex systems are systems composed of many heterogeneous components that interact with each other in parallel. Natural and computer-simulated complex systems self-organize spontaneously to produce global patterns of behavior that emerge from simple rules (Holland 1995). The link between abstract computational models and physical, chemical, and biological systems is through nonequilibrium thermodynamics (Prigogine 1980). Here, natural open systems are studied that self-organize by the dissipation of energy according to the second law of thermodynamics (Odum 1983). Once conceived as a bleak process, energy dissipation is now known to create "dissipative structures" that hasten dissipation (Prigogine 1980). In open systems, dissipative structures may appear spontaneously in hierarchies of larger and smaller spatial and temporal scales (Holling et al. 2002b). They are autocatalytic, meaning that the structure they form feeds back to capture and dissipate more energy. Dissipative structures can be characterized as evolutionary because they generate variation that is rewarded by the second law of thermodynamics for dissipative efficiency (Odum and Pinkerton 1955).
Biological organisms may be conceived as complex systems that evolve (in part) through natural selection, but many complex systems theorists see biological evolution as only one instance of a more general process of self-organization found at many scales (cf. Depew and Weber (1995) for review), including physical, chemical, and natural selection (Wicken 1988), and self-organization at scales of culture (Adams 1988), ecosystems (Ulanowicz 1986, Holling 1987), earth systems (Earnst 2000), or even the universe (Layzer 1991). The biosphere as a whole, therefore, is understood to be perpetually evolving, and the permanence that we perceive is the structure built by self-organization.

Although change is incessant, it is also directional, from concentration toward dissipation, with dissipative structures built in the process. It is an irreversible process driven by "time's arrow" of second-law entropy production (Prigogine and Stengers 1984). Self-organization divides natural systems into multiple temporal and spatial scales. A product of maximizing energy dissipation, nature is conceived to be discontinuous across scales, forming lumps or wholes in nested hierarchies (Holling et al. 2002b). An 
ecosystem is nested within the biosphere, while simultaneously being composed of nested scales selected by biological, chemical, and physical processes. Nature evolving is truly nature complex.

Melding this new ecology to the social sciences will require some care. Initial attempts have been made (e.g., Adams 1988, Tainter 1988, Lansing 1991, Gumerman and Gell-Mann 1994, Acheson and Wilson 1996, Berkes and Folke 1998, Abel 2000, Adams 2001, Bentley and Maschner 2003). Some authors emphasize the computational side of complex systems without appreciation for the thermodynamics and evolutionary components, and vice versa. Within the social sciences, some approaches ignore the political ecological in favor of the symbolic, technologies and material assets in favor of the structural, the force of human demographics in favor of any of the other components of "culture" (Abel 2003). These and other issues remain to be resolved in this young interdisciplinary effort.

Table 2. Human ecosystems then and now

Anthropologists occupied with:

New Directions:

1 Internal flows

2 Human-centered

3 Expected efficiency

4 Cultural functionalism

5 Regulation (negative feedback)

6 Homeostasis
Producing system indices, emergent behavior from simple rules

Multiple scales

Systemic energy dissipation

Directionality is dissipation

Self-organization (including evolution)

Pulsing, chaotic dynamics, adaptive cycle

\section{HUMAN ECOSYSTEMS THEN AND NOW}

Ecosystems ecology (as it was adopted by anthropologists) had features that were very different from current complex systems science (Table 2). Anthropologists put great effort into quantifying internal flows of food and goods to humans (Rappaport 1968, Kemp 1969, Thomas 1973, 1976). They expected to find energetic efficiency between energy expended and energy captured. It was often argued that symbolic or ritual behavior could be explained if it functioned to improve these efficiencies (Rappaport 1968). Human systems were assumed to be homeostatic, with negative feedbacks regulating the system in a state of high efficiency. Some of this work has since been abandoned by anthropologists, and other components, such as energetic efficiency and decision-making, have been successfully assailed by other middle- and micro-range methodologies, particularly amongst hunter-gatherer societies (see Winterhalder and Smith (2000) for review).

The "new ecology" of complex systems science is propelling human ecosystems research in new directions (Table 2). (1) Recognizing the daunting complexity of natural systems, some researchers are content to produce whole-system measurements or indices, rather than charting detailed internal flows of energy within a system (Odum 1996). Other researchers start with simple rules and endeavor to generate emergent behavior at meso- or macro-scales (Holland 1995). Although this may not appeal to those anthropologists who wish to map specific causal chains, it accepts that causality is multi-scaled and continuously self-organizing. The best explanation may exist at the scale of emergent patterns of selforganization in a complex system, not with the specifics of a political economy that are constantly shifting and reorganizing themselves. Causality and meaning clearly exist at human spatial and temporal scales. But in a nested, hierarchical human ecosystem, simple deterministic causal models are often overthrown by events from smaller or larger scales such as epidemics (e.g., HIV) or regional or global resource oscillations; human ecosystem research specifically attends to this complex nexus of causality. (2) The study of complex human ecosystems is not 
necessarily human centered, but rather focuses on the whole-system complex dynamics of matter, energy, and information from all temporal and spatial scales, including those that are uniquely human. If complex human ecosystems are the subject of study, and not humans per se, then it should not be surprising that (3) the efficient delivery of energy to humans within the system does not uniquely determine ecosystem structure and dynamics. Instead, as complex human ecosystems, the (4) directionality of the system is toward whole-system energy dissipation and selforganization. As explained above, (5) complex selforganizing systems are constantly evolving or renegotiating their state within the incessant flow of energy in natural open systems. The "regulation" provided by negative feedback is only one part of that dynamics. Which leads to another important difference between then and now, (6) complex systems are expected to exhibit nonlinear dynamics, which may take the form of pulsing or other chaotic dynamics, including multiple stable states or the adaptive cycle of Holling (1987). This differs dramatically from the homeostatic view of ecosystems of the past. These and other implications are discussed more fully below.

\section{THE ARTICLES}

This special issue of Conservation Ecology brings together international scholars in ecology and anthropology to consider the state of ecosystems ecology within anthropology, and to present possibilities for future directions in understanding human ecosystems. The anthropologists in the issue include specialists in the subdisciplines of archaeology, anthropological linguistics, cognitive anthropology, and cultural anthropology. Therefore, this issue provides an example of transdisciplinary research, both within and beyond anthropology. It explores the potential of ecosystems and complex systems to integrate disciplines and inform theory and methods in anthropology as a whole.

Some articles in this issue use less of the complex systems" "new ecology" while others use more, but all are efforts to conceptualize the human experiment as a human ecosystems experiment. They demonstrate that the questions we ask today and the problems we face as anthropologists, ecologists, or biological scientists require holistic and interdisciplinary answers.

Lepofsky et al. (2003) and Pereira and da Fonseca (2003) are two examples of careful and detailed studies that illustrate the difficulty of producing landscape histories or assessing anthropogenic changes in ecosystems. These studies offer both cautions and roadmaps for judging human impacts on complex human-ecological systems. They should interest a wide range of social scientists, but particularly archaeologists, who will be compelled to read the paleo-ecological record with even greater care and sophistication than in the past.

Wali et al. (2003) are interested in building sustainable urban environments in a case study of metropolitan Chicago. They conceptualize urban areas as ecosystems, a methodological approach that affords holistic and systemic analysis of urban humanenvironmental interactions. They advocate employing multidisciplinary teams and participatory community involvement to set conservation and environmental education goals.

The paper by Heemskerk et al. (2003) addresses the difficulty facing many interdisciplinary socialecological teams today, that of communicating across disciplines. They describe an innovative approach to producing conceptual models of human ecosystems in teamwork settings that builds on conventions previously established by both ecologists and anthropologists. They demonstrate that group model building can initiate discussion, reveal assumptions, and identify accord and discord between scientists from different disciplines, a much-needed practical solution to a problem/necessity of interdisciplinary research.

Three of the papers apply resilience theory and adaptive management (Gunderson and Holling 2002) to understanding complex human ecosystems. Trosper (2003) searches for three characteristics of resilience, buffering disturbance, self-organization, and learning, in a classic anthropological narrative - the potlatch system of the indigenous people of the Pacific Northwest. $\mathrm{He}$ contends that regional cultural continuity indicates resilient and sustainable human ecosystems, and explains such continuity as the result of specific forms of property rights, ethics, titleholding rules, and exchange systems. Toledo et al. (2003) examine the multiple-use subsistence strategies of contemporary indigenous peoples in Mexico as a case of adaptive management. They present details of multiple-use resource management in tropical forests that have emerged endogenously as responses to conditions of the contemporary world. Specifically, the multiple uses of species, resource rotation, landscape-patch management, and succession 
management are characterized as adaptive management that constitutes sustainable and biologically diverse human-ecosystem management. Peterson et al. (2003) employ a research tool of growing popularity, scenario planning, to predict future human ecosystems in the Northern Highlands Lake District (NHLD) of Wisconsin. With a keen appreciation for human ecosystem self-organization, predictability, unpredictability, and surprise, these researchers produced three starkly different yet reasonable scenarios for NHLD futures. This type of exercise exposes a wide range of possible outcomes, consistent with available scientific information, which can elicit creative planning and management.

Two other papers are synthetic explanations of the nature of complex human ecosystems, addressing themselves especially to the place and role of information in constructing and maintaining the human evolutionary experiment. Stepp et al. (2003) endeavor to bridge the divide between biological and human ecology by elucidating the unique informationprocessing capability of humans in ecosystems. Their cross-cultural and historical approach allows them to explore the existence of both complex functional and dysfunctional properties in human ecosystems. Salthe (2003) carries on his productive research program into self-organizing complex systems that he calls infodynamics (Salthe 1985, 1993). His metatheoretical approach is one of a number of impressive programmatic statements regarding complex systems that explore these natural, open systems (Prigogine and Stengers 1984, Ulanowicz 1986, Brooks and Wiley 1988, Kauffman 1993, Gell-Mann 1994, Holland 1995, Holling 1995, Odum 1996, Levin 1999, Gunderson and Holling 2002). In his article, he places humanity in a general model of the growth of complex dissipative structures that began with the universal disequilibrating event we know as the "Big Bang." Developing dissipative structures pass through three regimes of system growth and diversification, before eventual decline. Among the insights in his paper, Salthe places human ecosystems in a less "mature" state that taps more powerful energy flows, but produces more wastes of higher grade energy that act as pollutants.

The three acknowledged components of complex systems are information, matter, and energy. The final two papers emphasize the role of energy and matter in the self-organization of complex (non-equilibrium thermodynamic) human ecosystems. Tainter (Tainter et al. 2003) continues his work on energetic self- organization in human ecosystems (Tainter 1988) by proposing hypotheses about high and low energy gain civilizations and the transition between them. Tainter et al. (2003) state these hypotheses in a general form, and then apply them to beaver ecosystems and ecosystems containing fungus-farming ants. High-gain systems are roughly equivalent to Salthe's immature systems (Salthe 2003), which have a steep energy gradient to exploit (other comparisons can be made to Hollings' exploitation phase (Holling 1995) or Odum's growth or early succession model (Odum and Odum 2001)). Tainter et al. (2003) explore the historical record and explain the growth and collapse of the Roman Empire as a transition from high to low energy gain. Their approach equates low energy gain with debilitating bureaucracies and overly complex social organization.

Abel's article (Abel 2003) goes further in the application of complex systems principles of hierarchy, scale, and self-organization to the topic of social structural organization. He conceives human political-economic structure in terms of energy transformation hierarchies. As such, social structure is expected to self-organize to capture and use new energies when available, as in his case study of ecotourism development. Abel argues that large resource inflows associated with ecotourism have led to the emergence of a multi-scaled production hierarchy. As a complex system, the details of this sociocultural system self-organization are explicable after the fact in terms of structure and aggregate energy flows, although not predictable beforehand. His case study further exhibits an adaptive cycle in which self-organization transitions the island system from one stable state to another.

\section{IMPLICATIONS FOR ANTHROPOLOGY}

There are many implications to the application of the "new ecology" of ecosystems and complex systems science to the study of human ecosystems. One example already attracting much research is the application of the adaptive cycle model to the study of property regimes and institutions (Gunderson et al. 1995, Berkes and Folke 1998, Gunderson and Holling 2002). We do not attempt to summarize or identify all the possible implications in these closing paragraphs, but we do suggest a few less commonly discussed ones that we feel may have special significance for anthropologists given the historical trajectory of theory in our field. We hope this will illustrate the fruitfulness of the approach for social-ecological research. 


\section{Function and Directionality}

In earlier ecosystems models, it was expected that economic "adaptedness" could be measured as energetic efficiency, i.e., the ratio of energy capture to energy expenditure. Furthermore, cultural traits, such as religious practices, could be explained if they could be shown to regulate energy flows to people in a balanced, homeostatic ecosystem (Rappaport 1968). Complex human ecosystems guarantee humans no such privileged position or secure future. Rather, complex systems self-organize to dissipate energy by building structures (autocatalytic dissipative structures) that maximize useful dissipation (maximum empower in Odum's terms, the maximization of selfreinforcing energy flow, Odum (1996)). This rendition of dynamic nature is irreversible, nonlinear, constructive, multiscaled, and directional.

The resulting social structure in a complex human ecosystem is composed of impermanent and negotiated niches. From a political-ecological position, occupants of these niches can be understood to vie ceaselessly and occasionally violently to capture and maintain economic position in hierarchies of economic production and power. From the position of complex systems science applied to the long view of cultural evolution, it can be argued that there is no reason to expect sociocultural self-organization to make life "more secure" (White 1959) for all or even some fortunate inhabitants, as was long contended by materialist anthropologists. It is not expected that selforganization will lead to efficiency in energetic consumption for humans, per se, but rather that the whole human ecosystem will evolve to capture and use available energies efficiently, i.e., forming dissipative structures and maximizing self-reinforcing energy flow.

\section{System Functions and Individual Agency}

A flood of criticism against 1970s-style ecosystem anthropology was leveled at the ecosystem properties of homeostasis, self-regulation, and negative feedback. Preoccupied with balance and stability in systems, anthropologists were widely alleged to neglect the unbalanced and often contentious relationships between human groups for wealth or power. Historical change and human action or agency were said to be irrelevant in models of ecosystems that were viewed as cybernetic entities, relentlessly returning to a single climax state of high energetic efficiency.
In contrast, the perspective of complex systems selforganization presents a radically different landscape for human agency, negotiation, contest, and politicalecological evolution. System directionality is toward energy dissipation. This implies diversification and emergent structural hierarchy when energies are available. But the parameters of human-ecosystem structure and function are extremely broad. In complex systems, history is now important, constraining and channeling manifestations locally. All this suggests that individuals and groups can struggle and negotiate to effect change in relationships of power and production.

In these terms, it is also legitimate to discuss and critique the macro-scale "functions" of aggregate political-economic entities such as corporations, or military and government bureaucracies. From this perspective, complex behavioral patterns of entities larger than individuals become entrained if they amplify energy capture and use within a larger system. Larger-scale cause-effect or reward relationships can structure the environment in a way that channels individual behavior to fit, without explicitly directing individual behavior, or even directing it toward a specific end. The "end" is emergent from the aggregates of behavior. Aggregate behavior may rightly receive condemnation and individuals may indeed be responsible and held responsible. But cause undoubtedly also rests with the larger scales of corporate environment, resource flows, and global political economics, and agitation for solutions at these scales is equally legitimate.

\section{Multi-scaled Symbolic and Material Human Ecosystems}

Symbolic culture, sometimes referred to as belief systems, worldviews, cultural configurations, habitus, etc., can be viewed as a whole, possessing its own selforganization, yet simultaneously constrained and structured by its position in energy hierarchies. This conceptualization gives cultural anthropologists more autonomy to theorize about the structure and dynamics of their subject than was possible with earlier materialist research strategies (Harris 1979). At the same time, it suggests that anthropology can ill afford to ignore technological and structural self-organization associated with human material provisioning. The well-known autocatalytic nature of capitalism (M-CM', generation of "surplus value" (Marx 1967)) makes it a formidable growth engine that supported a population explosion and the formation of hierarchical 
world systems when fossil fuel energy became available. As growth slows with slowing energy production and increased demand, it will be vital to innovate at this political-ecological scale in search of alternative sustainable modes of production (Odum and Odum 2001).

\section{Time, Change, Evolution, and Humanity's Past}

Complex systems science is especially applicable to the study of change. The long view in anthropology is the purview of archaeologists, cultural evolutionists, and biological anthropologists. Cultural evolution can and should be studied as self-organization, with properties such as autocatalytic feedback, emergent political-ecological hierarchy, and adaptive cycles of pulse and collapse (Carneiro 1982, Adams 1988, Tainter 1988, Marcus 1998, Abel 2000, Adams 2001). The prehistoric "environment" must be viewed not as a backdrop but as a "moving target" negotiated incessantly with humans and with other processes at both larger and smaller scales. The prehistoric and historic records of emergent structural diversification and economic intensification, studied and re-studied by cultural evolutionists and archaeologists for decades (Morgan 1877, Steward 1955, White 1959, Fried 1967, Spencer 1973 (1877), Service 1975, Harris 1977, Johnson and Earle 1987, Harris 1989, Sanderson 1990), should be given a fresh look from a perspective that expects growth and collapse, a dynamic biophysical environment, shifting resources bases, and a hierarchical natural landscape. This view of "nature evolving" (Holling et al. 2002a) should slow the common practice of producing and then rejecting simplistic null hypotheses of environmental causality in favor of more idiosyncratic explanations. History and symbol have undoubted causal force in any equation, but in complex human ecosystems they must be contextualized within multiple evolving scales of energy dissipation. Methods that can provide a complete environmental accounting can be applied to archaeological sites and their evaluation (Odum 1996). Complex systems-informed environmental prehistories (Lepofsky et al. 2003, Pereira and da Fonseca 2003) should be co-constructed with human prehistories.

\section{Ecosystems Science and Critical Anthropology}

Most ecologists and ecosystems managers recognize at least two important roles for social scientists in interdisciplinary teams. One is as "facilitators" who can effectively crack the code of culture, overcoming social resistance and permitting smoother implementation of environmental policy (Groffman and Pace 1998). Another is as "interpreters" of traditional ecological knowledge and the blueprints for arguably sustainable ecosystem management and property institutions (McCay and Acheson 1987, Berkes and Folke 1998). These two roles are of great value to ecosystems management as it is practiced today.

However, the "management" orientation of ecosystem science does leave some questions unasked, some issues unexplored - topics of great interest to both cultural anthropologists and archaeologists. Anthropologists may be interested in contextualizing contemporary human ecosystems and ecosystem management itself within their historical and evolutionary trajectories of power, economics, and natural resource limits (Crumley 1994, McNeill 2001), historical trajectories that include collapse or contraction as often as growth (Tainter 1988, Marcus 1998, Redman 1999, Adams 2001). These contributions may not accord with the two roles above and with the popular narrative of sustainability and ecosystem management. Rather than rational ecosystem management, anthropologists may look at the history of expansive states or the contemporary world system (Wallerstein 1974) and see politicaleconomic elites or corporations constructing the "natural resource" debates and management context for reasons that have less to do with conservation and much to do with the age-old contests for power and material assets (Greenberg and Park 1994, Escobar 1998). Can the study of human ecosystems or complex systems science incorporate these phenomena within its theoretical structure? Is there ecosystem or complex systems theory of structure or function that can contribute explanations of the emergence and evolution of subsistence intensification, of inequality, class, power, warfare, and, in general, human ecosystem history and present? We believe so. Selforganization, hierarchy, scale, dissipative structures, co-evolution, history, nonlinear dynamics, these and other features of complex systems are ripe for application to the past and present record of human ecosystem structure and dynamics.

Contemporary anthropological research over much of the world's surface finds traditional subsistence strategies and ecological knowledge overlaid by multinational scales of resource extraction and concentration, forming hierarchically organized states and world systems (Denemark et al. 2000, Hornborg 2001). Within that context must be located "ecosystem 
management" bureaucracies. Explanation of the occasional failures of ecosystem management may often be found at this scale, at the scale of contemporary world systems that depend on nonrenewable resource extraction for their maintenance and growth. Some anthropologists, therefore, who have explored historic and prehistoric pulse and collapse dynamics or the political economics of capitalist states, have questioned the "sustainability" narrative and have foreseen more radical politicalecological reorganizations (Escobar 1996). Global economic contraction or dramatic political-economic reorganization are not topics that bureaucracies or many funding agencies want to consider. If, however, human-ecosystems researchers will not broach the subject, who will? Can neo-classical economics understand a no-growth world (Hall et al. 2001)? Are disciplinary social scientists in a position to understand how social upheavals relate to falling crop yields, water wars, regional ecosystem perturbations, or simply to nearly invisible, incremental reductions in the energy sources that power so much of our world (Meadows et al. 1992, McNeill 2001, Odum and Odum 2001)?

\section{Anthropology and Science}

Holling has described "two streams" of science, one experimental, reductionist, and narrowly disciplinary, and the other interdisciplinary, integrative, historical, analytical, comparative, and experimental at appropriate scales (Holling 1998). The second integrative stream is the science of complex systems. Anthropologists have had difficulty forcing their complex subject of study into the rigors of the traditional first stream of science. Case study comparisons are often our only choice. Historical peculiarities are unavoidable. Human ecosystems are vastly complex, and single dependent variables often lead to unconvincing explanations. The research in this special issue suggests a different direction. The context of our human experience is tremendously complex and endlessly evolving. An interdisciplinary science that addresses itself to evolving systems with determinant processes at multiple scales of space and time could be a better fit for anthropology.

\section{A LAST WORD}

The conversation between anthropologists and ecologists goes back a long way, even before each discipline came into its own. This conversation has not been a steady dialogue, but has been marked by periods of intense interest and borrowing, followed by spans of indifference or even neglect. Much of the borrowing has been from biological ecology to human ecology by social scientists who sought new insights to understand human-environment interactions. Yet, many of the formative concepts in biological ecology, such as community or hierarchy, were first borrowed at the turn of the century from human-oriented disciplines such as sociology and economics (Young 1974). Later generations of social scientists would then come to borrow these concepts back in the development of human ecology. What is important to note is that, far from being continuous, this conversation has been often interrupted, at times misunderstood, and often in need of translation. This "unfinished conversation," to borrow Sullivan's metaphor (Sullivan 1989), continues to this day; this collection of articles is our attempt at moving it along.

We are committed to the premise that to better understand ecosystems we need to better understand the dominant organism on this planet. To do so, we feel, will require a mature integration of anthropology and the ecosystem sciences in both theory and practice. There are many obstacles to integration between biological and human ecology but perhaps the most stubborn continue to be disciplinary boundaries and the inherent complexity of the subject matter. We hope that the boundary problem is taking care of itself as journals such as Conservation Ecology and Ecosystems succeed in attracting a wide range of research. The second problem too is now being addressed with scientific methods that focus specifically on the complexity of systems.

One important question to consider is "What will be the intellectual and institutional settings or environments in which individuals are trained to take up this challenge?" The new breed of integrated ecologists will need to be fluent in their home discipline and competent in a range of other complementary disciplines. They will need to let the problem at hand guide the choice of discipline(s) to apply, rather than let the discipline determine the limits of the problem itself. We are optimistic that this challenge is being met and that the conversation will continue.

Responses to this article can be read online at: http://www.consecol.org/vol7/iss3/art12/responses/index.html 


\section{LITERATURE CITED}

Abel, T. 2000. Ecosystems, sociocultural systems, and ecological economics for understanding development: the case of ecotourism on the island of Bonaire, N.A. Dissertation, University of Florida, Gainesville, Florida, USA. [online] URL: http://etd.fcla.edu/etd/uf/2000/ane0595/Abel.pdf.

Abel, T. 2003. Understanding complex human ecosystems: the case of ecotourism on Bonaire. Conservation Ecology 7(3): 10 [online] URL: http://www.consecol.org/vol7/iss3/art10.

Acheson, J. M., and J. A. Wilson. 1996. Order out of chaos: the case for parametric fisheries management. American Anthropologist 98(3):979-994.

Adams, R. N. 1988. The eighth day: social evolution as the self-organization of energy. University of Texas Press, Austin, Texas, USA.

Adams, R. McM. 2001. Complexity in archaic states. Journal of Anthropological Archaeology 20:345-360.

Bentley, R. A., and H. D. G. Maschner, editors. 2003. Complex systems and archaeology. The University of Utah Press, Salt Lake City, Utah, USA.

Berkes, F., and C. Folke, editors. 1998. Linking social and ecological systems: management practices and social mechanisms for building resilience. Cambridge University Press, Cambridge, UK.

Biersack, A. 1999. Introduction: from the "new ecology" to the new ecologies. American Anthropologist 101:5-18.

Boyd, R., and P. J. Richerson. 1985. Culture and the evolutionary process. The University of Chicago Press, Chicago, Illinois, USA.

Brooks, D. R., and E. O. Wiley. 1988. Evolution as entropy: toward a unified theory of biology. University of Chicago Press, Chicago, Illinois, USA.

Carneiro, R. L. 1982. Successive reequilibrations as the mechanism of cultural evolution. Pages 110-115in W. C. Schieve and P.M. Allen, editors. Self-organization and dissipative structures: applications in the physical and social sciences. University of Texas Press, Austin, Texas, USA.

Cavalli-Sforza, L. L., and M. W. Feldman. 1981. Cultural transmission and evolution: a quantitative approach. Princeton University Press, Princeton, New Jersey, USA.

Crumley, C. L., editor. 1994. Historical ecology: cultural knowledge and changing landscapes. School of American Research Press, Santa Fe, New Mexico, USA.
Denemark, R. A., J. Friedman, B. K. Gills, and G. Modelski, editors. 2000. World system history: the social science of long-term change. Routledge, London, UK.

Depew, D. J., and B. H. Weber. 1995. Darwinism evolving: systems dynamics and the genealogy of natural selection. The MIT Press, Cambridge, Massachussetts, USA.

Durham, W. H. 1991. Coevolution: genes, culture, and human diversity. Stanford University Press, Stanford, California, USA.

Earnst, W. G., editor. 2000. Earth systems: processes and issues. Cambridge University Press, Cambridge, UK.

Ellen, R. 1982. Environment, subsistence and system: the ecology of small-scale social formations. Cambridge University Press, Cambridge, UK.

Escobar, A. 1996. Construction nature: elements for a poststructuralist political ecology. Futures 28(4):325-343.

Escobar, A. 1998. Whose knowledge, whose nature? Biodiversity, conservation, and the political ecology of social movements. Journal of Political Ecology 5:53-82.

Fried, M. H. 1967. The evolution of political society: an essay in political anthropology. Random House, New York, New York, USA.

Gell-Mann, M. 1994. The quark and the jaguar: adventures in the simple and the complex. W. H. Freeman, New York, New York, USA.

Golley, F. B. 1993. A history of the ecosystem concept in ecology: more than the sum of the parts. Yale University Press, New Haven, Connecticut, USA.

Greenberg, J. B., and T. K. Park. 1994. Political ecology. Journal of Political Ecology 1:1-11.

Groffman, P. M., and M. L. Pace. 1998. Synthesis: what kind of a discipline is this anyhow? Pages 473-481 in M. L. Pace and P. M. Groffman, editors. Successes, limitations, and frontiers in ecosystem science. Springer-Verlag, New York, New York, USA.

Gumerman, G. J., and M. Gell-Mann, editors. 1994. Understanding complexity in the prehistoric southwest. Addison-Wesley, Reading, Massachussetts, USA.

Gunderson, L. H., and Holling C. S., editors. 2002. Panarchy: understanding transformations in human and natural systems. Island Press, Washington, D.C., USA.

Gunderson, L. H., C. S. Holling, and S. S. Light. 1995. Barriers broken and bridges built: a synthesis. Pages 489 532 in L. H. Gunderson, C. S. Holling, and S. S. Light, editors. Barriers and bridges to the renewal of ecosystems and institutions. Columbia University Press, New York, New York, USA. 
Gunderson, L. H., C. S. Holling, and S. S. Light, editors. 1995. Barriers and bridges to the renewal of ecosystems and institutions. Columbia University Press, New York, New York, USA.

Hagen, J. B. 1992. An entangled bank: the origins of ecosystem ecology. Rutgers University Press, New Brunswick, New Jersey, USA.

Hall, C. A. S., D. Lindenberger, R. Kummel, T. Kroeger, and W. Eichhorn. 2001. The need to reintegrate the natural sciences with economics. BioScience 51(8):663-673.

Harris, M. 1977. Cannibals and kings: the origins of cultures. Random House, New York, New York, USA.

Harris, M. 1979. Cultural materialism: the struggle for a science of culture. Random House, New York, New York, USA.

Harris, M. 1989. Our kind: the evolution of human life and culture. HarperCollins Publishers, New York, New York, USA.

Heemskerk, M., K. Wilson, and M. Pavao-Zuckerman. 2003. Conceptual models as tools for communication across disciplines. Conservation Ecology 7(3):8. [online] URL: http://www.consecol.org/vol7/iss3/art8.

Holland, J. H. 1995. Hidden order: how adaptation builds complexity. Addison-Wesley, Reading, Massachussetts, USA.

Holling, C. S. 1978. Adaptive Environmental Assessment and Management. John Wiley, London, UK.

Holling, C. S. 1986. The resilience of terrestrial ecosystems: local surprise and global change. Pages 292317 in W. C. Clark and R. E. Munn, editors. Sustainable development of the biosphere. Cambridge University Press, Cambridge, UK.

Holling, C. S. 1987. Simplifying the complex: the paradigms of ecological function and structure. European Journal of Operational Research 30:139-146.

Holling, C. S. 1995. What barriers? What bridges? Pages 334 in L. H. Gunderson, C. S. Holling, and S. S. Light. editors. Barriers and bridges to the renewal of ecosystems and institutions. Columbia University Press, New York, New York, USA.

Holling, C. S. 1998. Two cultures of ecology. Conservation Ecology 2. [online] URL: http://www.consecol.org/vol2/iss2/art4.

Holling, C. S., L. H. Gunderson, and D. Ludwig. 2002a. In quest of a theory of adaptive change. Pages 3-22 in L. H. Gunderson and C. S. Holling, editors. Panarchy: understanding transformations in human and natural systems. Island Press, Washington, D.C., USA.
Holling, C. S., L. H. Gunderson, and G. D. Peterson. 2002b. Sustainability and panarchies. Pages 63-102 in L. H. Gunderson and C. S. Holling, editors. Panarchy: understanding transformations in human and natural systems. Island Press, Washington, D.C., USA.

Hornborg, A. 2001. The power of the machine: global inequalities of economy, technology, and environment. AltaMira Press, Walnut Creek, California, USA.

Johnson, A. W., and T. Earle. 1987. The evolution of human societies: from foraging group to agrarian state. Stanford University Press, Stanford, California, USA.

Kauffman, S. A. 1993. Origins of order: self organization and selection in evolution. Oxford University Press. Oxford, UK.

Kemp, W. B. 1969. The flow of energy in a hunting society. Scientific American 224:105-115.

Kimmins, J. P. 1987. Forest ecology. MacMillan, New York, New York, USA.

Kottak, C. P. 1999. The new ecological anthropology. American Anthropologist 101:23-35.

Lansing, S. J. 1991. Priests and programmers: technologies of power in the engineered landscape of Bali. Princeton University Press, Princeton, New Jersey, USA.

Layzer, D. 1991. Cosmogenesis: the growth of order in the universe. Oxford University Press, Oxford, UK.

Lepofsky, D., E. K. Heyerdahl, K. Lertzman, D. Schaepe, and B. Mierendorf. 2003. Historical meadow dynamics in southwest British Columbia: a multidisciplinary analysis. Conservation Ecology 7(3):5. [online] URL: http://www.consecol.org/vol7/iss3/art5.

Levin, S. 1998. Ecosystems and the biosphere as complex adaptive systems. Ecosystems 1:431-436.

Levin, S. 1999. Fragile dominion: complexity and the commons. Perseus, Cambridge, UK.

Little, P. E. 1999. Environments and environmentalisms in anthropological research: facing a new millennium. Annual Review of Anthropology 28:253-84.

Marcus, J. 1998. The peaks and valleys of ancient states: an extension of the dynamic model. Pages 59-94 in G. M. Feinman and J. Marcus, editors. Archaic States. School of American Research Press, Santa Fe, New Mexico, USA.

Marx, K. 1967 (1867). Capital, Vol. I. International Publishers, New York, New York, USA.

McCay, B., and J. M. Acheson, editors. 1987. The question of the commons: the culture and ecology of communal resources. University of Arizona Press, Tucson, Arizona, USA. 
McNeill, J. R. 2001. Something new under the sun: an environmental history of the Twentieth-century world. Norton, New York, New York, USA.

Meadows, D. H., D. L. Meadows, and J. Randers. 1992. Beyond the limits: confronting global collapse, envisioning a sustainable future. Chelsea Green Publishing Company, White River Junction, Vermont, USA.

Moran, E. F. 1990. The ecosystem concept in anthropology. Westview Press, Boulder, Colorado, USA.

Morgan, L. H. 1877. Ancient society. Holt, Rinehart and Winston, New York, New York, USA.

Odum, E. P. 1953. Fundamentals of ecology. W. B. Saunders, Philadelphia, Pennsylvania, USA.

Odum, H. T. 1983. Systems ecology. John Wiley, New York, New York, USA.

Odum, H. T. 1996. Environmental accounting: emergy and decision making. John Wiley, New York, New York, USA.

Odum, H. T., and E. C. Odum. 2001. A prosperous way down: principles and policies. University Press of Colorado, Niwot, Colorado, USA.

Odum, H. T., and R. C. Pinkerton. 1955. Time's speed regulator: the optimum efficiency for maximum power output in physical and biological systems. American Scientist 43:321-343.

O'Neill, R. V., D. L. DeAngelis, J. B. Waide, and T. F. H. Allen. 1986. A hierarchical concept of ecosystems. Princeton University Press, Princeton, New Jersey, USA.

Pace, M. L., and P. M. Groffman, editors. 1998. Successes, limitations, and frontiers in ecosystem science. Springer-Verlag, New York, New York, USA.

Pereira, P. M., and M. P. da Fonseca. 2003. Nature vs. nurture: the making of the montado ecosystem. Conservation Ecology 7(3):7. [online] URL: http://www.consecol.org/vol7/iss3/art7.

Peterson, G. D., T. D. Beard, Jr., B. E. Beisner, E. M. Bennett, S. R. Carpenter, G. S. Cumming, C. L. Dent, and T. D. Havlicek. 2003. Assessing future ecosystem services: a case study of the Northern Highlands Lake District, Wisconsin. Conservation Ecology 7(3):1. [online] URL: http://www.consecol.org/vol7/iss3/art1.

Pickett, S. T. A., and M. L. Cadenasso. 2002. The ecosystem as a multidimensional concept: meaning, model, and metaphor. Ecosystems 5:1-10.

Prigogine, I. 1980. From being to becoming: time and complexity in the physical sciences. W. H. Freeman and Company, New York, New York, USA.

Prigogine, I., and I. Stengers. 1984. Order out of chaos: man's new dialogue with nature. Bantam Books, Toronto, Ontario, Canada.

Rappaport, R. A. 1968. Pigs for the ancestors: ritual in the ecology of a New Guinea people. Yale University Press, New Haven, Connecticut, USA.

Redman, C. L. 1999. Human impact on ancient environments. The University of Arizona Press, Tucson, Arizona, USA.

Rindos, D. 1986. The genetics of cultural anthropology: toward a genetic model for the origin of the capacity for culture. Journal of Anthropological Archaeology 26:65-88.

Salthe, S. N. 1985. Evolving hierarchical systems: their structure and representation. Columbia University Press, New York, New York, USA.

Salthe, S. N. 1993. Development and evolution: complexity and change in biology. The MIT Press, Cambridge, Massachussetts, USA.

Salthe, S. N. 2003. Infodynamics, a developmental framework for ecology/economics. Conservation Ecology 7(3):3. [online] URL: http://www.consecol.org/vol7/iss3/art3.

Sanderson, S. K. 1990. Social evolutionism: a critical history. Blackwell, Cambridge, Massachussetts, USA.

Scoones, I. 1999. New ecology and the social sciences: what prospects for a fruitful engagement? Annual Review of Anthropology 28:479-507.

Service, E. R. 1975. Origins of the state and civilization: the process of cultural evolution. W. W. Norton and Company, New York, New York, USA.

Smith, E. A. 1984. Anthropology, evolutionary ecology, and the explanatory limitations of the ecosystem concept. Pages 51-85 in E. F. Moran, editor. The ecosystem concept in anthropology. Westview Press, Boulder, Colorado, USA.

Spencer, H. 1973 (1877). The Evolution of Society. Pages 6-28 in P. Bohannan and M. Glazer, editors. High points in anthropology. Alfred A. Knopf, Inc., New York, New York, USA.

Stepp, J. R., E. C. Jones, M. Pavao-Zuckerman, D. Casagrande, and R. K. Zarger. 2003. Remarkable properties of human ecosystems. Conservation Ecology 7(3):11. [Online] URL: http://www.consecol.org/vol7/iss3/art11.

Steward, J. H. 1955. Theory of culture change: the methodology of multilinear evolution. University of Illinois Press, Urbana, Illinois, USA.

Sullivan, P. 1989. Unfinished conversations: mayas and foreigners between two world wars. University of California Press, Berkeley, California, USA. 
Tainter, J. 1988. The collapse of complex societies. Cambridge University Press, Cambridge, UK.

Tainter, J., T. F. H. Allen, A. Little, and T. W. Hoekstra. 2003. Resource transitions and energy gain: contexts of organization. Conservation Ecology 7(3):4. [Online] URL: http://www.consecol.org/vol7/iss3/art4.

Tansley, A. G. 1935. The use and abuse of vegetational concepts and terms. Ecology 16(3):284-307.

Thomas, R. B. 1973. Human adaptation to a high andean energy flow system. The Pennsylvania State University, University Park, Pennsylvania, USA.

Thomas, R. B. 1976. Energy flow at high altitude. Pages 379-404 in P. T. Baker and M. A. Little, editors. Man in the Andes: a multidisciplinary study of high-altitude quechua. Dowden, Hutchinson and Ross, Inc., Stroudsburg, Pennsylvania, USA.

Toledo, V. M., B. Ortiz-Espejel, L. Cortés, P. Moguel, and M. D. J. Ordoñez. 2003. The multiple use of tropical forests by indigenous peoples in Mexico: a case of adaptive management. Conservation Ecology 7(3):9. [online] URL: http://www.consecol.org/vol7/iss3/art9.

Trosper, R. L. 2003. Resilience in pre-contact Pacific Northwest social ecological systems. Conservation Ecology 7(3):6. [online] URL: http://www.consecol.org/vol7/iss3/art6.

Ulanowicz, R. E. 1986. Growth and development: ecosystems phenomenology. Springer-Verlag, New York, New York, USA.

van de Vijver, G., S. N. Salthe, and M. Delpos, editors. 1998. Evolutionary systems: biological and epistemological perspectives on selection and self-organization. Kluwer, Dordrecht, The Netherlands.

Vayda, A. P. 1983. Progressive contextualization: methods for research in human ecology. Human Ecology 11:265281 .

Vayda, A. P., and B. McCay. 1975. New directions in ecology and ecological anthropology. Annual Review of Anthropology 4:293-306.

Vogt, K. A., J. C. Gordon, J. P. Wargo, D. J. Vogt, H. Asbjornsen, P. A. Palmiotto, H. J. Clark, J. L. O'Hara, W. S. Keeton, T. Patel-Weynand, and E. Witten, editors. 1997. Ecosystems: balancing science with management. Springer-Verlag, New York, New York, USA.

Wali, A., G. Darlow, C. Fialkowski, M. Tudor, H. del Campo, and D. Stotz. 2003. New methodologies for interdisciplinary research and action in an urban ecosystem in Chicago. Conservation Ecology 7(3):2. [online] URL: http://www.consecol.org/vol7/iss3/art2.

Wallerstein, I. 1974. The modern world-system I: capitalist agriculture and the origins of the European world-economy in the Sixteenth century. Academic Press, New York, New York, USA.

Walters, C. J. 1986. Adaptive management of renewable resources. MacMillan, New York, New York, USA.

White, L. A. 1959. The evolution of culture: the development of civilization to the fall of Rome. McGrawHill Book Company, New York, New York, USA.

Wicken, J. S. 1987. Evolution, thermodynamics, and information: extending the Darwinian program. Oxford University Press, New York, New York, USA.

Wicken, J. S. 1988. Thermodynamics, evolution, and emergence: ingredients for a new synthesis. Pages 139-169 in D. J. Depew and B. H. Weber, editors. Entropy, information, and evolution: new perspectives on physical and biological evolution. The MIT Press, Cambridge, Massachussetts, USA.

Winterhalder, B. 1984. Reconsidering the ecosystem concept. Reviews in Anthropology 11:301-307.

Winterhalder, B., and E. A. Smith. 2000. Analyzing adaptive strategies: human behavioral ecology at twentyfive. Evolutionary Anthropology 9:51-72.

Young, G. L. 1974. Human ecology as an interdisciplinary concept: a critical inquiry. Advances in Ecological Research 8:1-105. 